\title{
The Relationship between School/Department Rankings, Student Achievements, and Student Experiences: The Case of Psychology
}

\author{
Douglas M. Stenstrom \\ California State University \\ Los Angeles, \\ Los Angeles, CA, USA \\ dstenst@calstatela.edu
}

\author{
Mathew Curtis and Ravi lyer \\ University of Southern California, \\ Los Angeles, CA, USA
}

mcurtis@usc.edu

ravi@ranker.com

\begin{abstract}
What predicts academic success during graduate school? What are the experiences of graduate students in terms of happiness, stress level, relationships in the program, and feelings of autonomy/competence? Responses from 3,311 graduate students from all psychological disciplines in the US and Canada were collected to answer questions involving (1) the relationship between student-level variables and department/school rankings (US News \& World Report, Carnegie Foundation, National Research Council), (2) the determinants of important student-level variables such as number of publications, posters, and life satisfaction, and (3) examining the variables year-by-year in the program to explain changes over time at different points in the graduate career. Results reveal the degree to which certain aspects of higher ranked departments/schools impact student achievements such as number of publications and teaching experience. The results also reveal a unique year-by-year progression including a consistent decrease of happiness for every year in graduate school. While the findings were collected in psychology, the answers to these questions may resonate with graduate students across disciplines that are experiencing similar forces that characterize the graduate school experience. The results can also inform current conversations about the direction of higher education and the value of the graduate school experience.
\end{abstract}

Keywords: department rankings, students, publications, happiness, life satisfaction

\section{Introduction}

What predicts academic success during graduate school? How does the average student evaluate his or her graduate school experience?

Material published as part of this publication, either on-line or in print, is copyrighted by the Informing Science Institute. Permission to make digital or paper copy of part or all of these works for personal or classroom use is granted without fee provided that the copies are not made or distributed for profit or commercial advantage AND that copies 1) bear this notice in full and 2) give the full citation on the first page. It is permissible to abstract these works so long as credit is given. To copy in all other cases or to republish or to post on a server or to redistribute to lists requires specific permission and payment of a fee. Contact Publisher@,InformingScience.org to request redistribution permission.
The current research started while the authors were in graduate school studying social psychology and wondered about the relative experiences of other graduate students. Through conducting a national survey of psychology graduate students, we sought to quantify aspects of the graduate school experience. We hoped to understand what predicted professional success as well as what pre- 
dicted the subjective experience of life in graduate school as students navigate the program yearby-year.

To address these two main focuses (objective academic benchmarks and subjective experience of graduate school), the current paper reports on a survey of 3,311 graduate students from all psychological disciplines that addresses different aspects of individual accomplishments and experiences while in graduate school at each year in the graduate program. To fully understand the influences of these variables, we integrated our survey with the newly released preeminent assessment of department-level rankings from the National Research Council (Assessment of Research Doctoral Programs, n.d.) as well as school-level rankings systems from the Carnegie Classification of Institutions of Higher Education (Carnegie 2005 Edition, n.d.) and the U.S. News and World Report rankings (US News \& World Report, 2012). Through integrating all three levels (i.e., student-level variables from our national survey, department-level rankings compiled from faculty variables, and school-level rankings), it is possible to examine previously unaddressed associations and predictors of each level. For example, what is the relationship between individual achievements like publications/posters and psychological needs [autonomy, relationships, competency] (Deci \& Ryan, 2000)? Is graduate school meeting the psychological needs of students at different years in the program? What predicts happiness or competence in graduate school? Are students at more prestigious departments or colleges happier and more productive?

More precisely, the current research addresses our two main focuses (objective accomplishments and subjective experiences) by investigating (1) how department/school rankings are associated with these student variables, (2) what predicts these student variables, and (3) examining the student variables year-by-year in the program to explain changes over time and allow the reader to identify comparative benchmarks at different points in the graduate career. There are many potential consumers of these results. First, the answers presented will hopefully help other graduate students understand the factors that broadly affect graduate students achievements and experiences. Second, the data is valuable to institutional and national policy makers in formulating and administering policy for graduate education. Finally, the data allows departments and schools to quantify the effect of rankings, which are a focus of many institutions, in terms of objective student accomplishments and subjective student experiences while in graduate school.

\section{Method}

\section{Participants}

Participants were 4,162 graduate students (3,311 $\mathrm{PhD}$ and $851 \mathrm{MA})$ in psychology programs in the United States and Canada. The current research focuses on the 3,311 PhD students because the newly released department-level ranking system is restricted to assessment of doctoral programs. The majority of participants were younger than 30 years old $(M=28.42, M d n=27.00, S D$ $=5.41$ ) and female (910 males and 2,387 females). Data was collected between May-June 2007 at the same time that the National Research Council (NRC) department-level ranking system was compiled, and after years of processing the data the NRC ranking system was eventually released to the public in 2011 (National Research Council, 2011). In the original dataset of 4162 respondents, an additional 32 did not indicate program type (MA, $\mathrm{PhD}$ ) so we opted for a conservative approach of removing them from data analysis since we could not confirm they were PhD students. The data was collected at the end of the academic year in May-June, but an additional 41 completed the survey outside that time frame, trickling in until March of the following year. In order to avoid potential confounds of a few respondents answering the same survey questions months later after they had more time to accumulate achievements (e.g., publications), those respondents were not included in the analysis. Participants were recruited via an email sent to the contact person of each psychology graduate department listed in the APA book "Graduate Study 
in Psychology" (American Psychological Association, 2007) and sent directly to the email addresses of graduate students listed on the department websites of programs listed in the same book. The email to the contact person requested that they forward the survey link to all graduate students within their department.

\section{Materials and Procedure}

Participants completed a 35-question survey that began with measuring the type of program (masters, $\mathrm{PhD}$ ), their current year in the program, and area of specialization. Unless otherwise specified below, the response format was on a 0 to $15+$ scale. The next set of questions assessed achievements during graduate school: (1) Publications: Four questions assessed scholarship according to the total number of publications (published and in press), number of first author publications, second author publications, and third+ author publications; (2) Publication-related questions: Two more questions were used to fully understand the role of publications within the field by assessing how many publications were peer reviewed and how many were "in submission"; (3) Research Activity: Three questions assessed ongoing research activity according to how many manuscripts in preparation (i.e., not yet submitted for peer review), how many ongoing research projects for which the respondent would be first author, and how many ongoing projects for which the respondent would be second author or more; (4) Conferences: Two questions assessed conference related activity of how many conferences attended and how many poster presentations listed on the CV; (5) Teaching-related Experience: Two questions assessed teaching-related experience regarding the number of time as a Teaching Assistant and how many times the respondent was the primary instructor.

The next set of questions assessed the perceptions and experiences during graduate school: (1) Life/Graduate School Satisfaction: Three questions assessed overall satisfaction with their graduate school and life in general. Responses were on a 7-point scale. The first question was "If you consider your life overall, how satisfied would you say you are nowadays?" with end points of "very unsatisfied" to "very satisfied". The second question was "How unhappy/happy are you with being in graduate school?" with endpoints of "unhappy" and "happy". The third question was "How would you rate your overall stress level from being in graduate school?" with endpoints "no stress" and "stress"; (2) Psychological Need Satisfaction: Three questions assessed the three basic psychological needs within self-determination theory - relatedness, autonomy, and competency (Deci \& Ryan, 2000). Responses were on a 7-point scale from 1 (disagree) to 7 (agree). The questions were "I have good relationships with the people in my program", "I am free to make decisions about my work in my program.", and "I feel competent when doing work in my program."; (3) Recommend Graduate School: A single question asked participants "Would you recommend psychology graduate school to others who are thinking of going to graduate school?" using a 7-point scale from 1 (not at all) to 7 (very much).

The subsequent set of questions assessed graduation plans: (1) Time to Graduation: Two questions assessed time to degree completion: "How many total years do you expect it will take you to graduate?", and "Are you going to graduate at the time you expected to graduate when you started the program?"; (2) Post-graduate Plans: Three questions assessed their plans after graduate school: "Do you intend to try and get a job in academia?", and "Does your advisor expect you to try to get a job in academia" The option choices included (a) no, (b) yes, at $\mathrm{PhD}$ granting school with primary focus on research, (c) yes, at $\mathrm{PhD}$ granting school which has less focus on research, (d) yes, at Masters granting school, (e) yes, at Liberal arts school, (f) yes, at 2-year school (e.g., Community College), and (g) don't know. An additional question assessed future employment: "What do you think your chances are of obtaining employment in the type of job you want after graduating from your program?" on 7-point from "very low" to "very high". 
The final set of questions assessed demographics and school-name: (1) Demographics: Four questions assessed age, gender, ethnicity, and level of debt. The question about debt asked, "Are you in debt due to graduate school?" with increments of five thousand, starting at $\$ 0 \mathrm{debt}$, and moving up to $\$ 51 \mathrm{~K}+$ of debt; (2) Name of University: Finally, participants were asked the name of their university/school which allowed matching of participant responses with the data from the ranking system datasets.

Another set of questions in the survey asked about employment (i.e., have you successfully obtained employment, how many jobs have you applied for within academia and outside of academia). Those questions are not contained in the current analysis as they were reported in another publication (Stenstrom, Curtis, \& Iyer, 2013) about how rankings and individual accomplishments predict different types of employment after the PhD program. The two questions in the current paper about intentions for academic employment were dichotomized in Table 1 (at end of paper) since the original seven categories do not permit correlational analysis with the continuous ranking systems. It is also important to point out that the scale range for some questions was 0 to $15+$ so it creates an artificial ceiling for responding. Although this has the effect of reducing the effect of outliers when looking at the mean levels in some analysis, it does provide less data than having a completely continuous scale. In terms of the data collection, the current study did not explicitly assess whether the respondents were post-docs, for example, so it is possible some postdocs responded affirmatively to the question asking whether they were in a $\mathrm{PhD}$ program and were thus included in the analysis. It is important to point out that all self-report data is susceptible to inaccurate self-reporting or misunderstanding of the questions.

\section{Department-level and School-level Ranking Systems}

The National Research Council's (NRC) Data-Based Assessment of Research-Doctorate Program is a department-level dataset that produced both overall rankings (R-rankings) and dimensional rankings of three specific attributes of departmental characteristics (Research Activity, Student Support and Outcomes, and Diversity). The NRC was formed in 1916 as a research arm of the United States National Academies and is charged with conducting the assessment of doctoral programs in the United States every 10 years (History of National Academies, n.d; National Academies Press, n.d.). Data was collected in Fall 2006 and Spring 2007. After checking the data with the institutions through Fall 2007 data collection concluded Spring 2008. The report states that all data are for the 2005-2006 academic year (Ostriker, Holland, Kuh, \& Voytuk, 2011). The revised dataset used in the current paper was released to the public on April 2011 (National Research Council, 2011). The ranking system ranged from 1 to 225 , with a lower number representing a better ranked school.

The NRC collected data on individual items of department/faculty attributes (e.g., average number of faculty publications) that were composited into the three dimensional rankings (Research Productivity, Student Support, Diversity), and the dimensional rankings formed part of the basis for the overall weighted rankings. The NRC reported the $5^{\text {th }}$ and $95^{\text {th }}$ Percentile for all the rankings to avoid directly providing a single ranking for a department. Given that there is an immensely high correlation between the $5^{\text {th }}$ and $95^{\text {th }}$ percentile scores within each ranking ( $r$ s ranging between .90 to $.98, p \mathrm{~s}<.001$ ), future data analysis for brevity sake will only include the $5^{\text {th }}$ Percentile scores. The NRC reported two overall rankings $-\mathrm{R}$ rankings and $\mathrm{S}$ ranking. Given the immensely high correlation between the R-rankings and S-rankings $(r \mathrm{~s}>.96, p \mathrm{~s}<.001)$ and given that those two rankings include the same variables but only provide different weights to the variables, future data analysis for brevity sake will only include the R-Rankings. R-Rankings were chosen over S-Rankings because the former are based upon faculty within the field rating a sample of actual psychology programs. Detailed information about how each ranking was col- 
lected and processed can be found on the NRC website (Assessment of Research Doctoral Programs, n.d.).

The school-level datasets also contained a ranking system where a lower number represents a better ranked school. The Carnegie Classification of Institutions of Higher Education data (Carnegie) contains the revised classification based upon an updated ranking system in which $\mathrm{PhD}$ graduate programs are placed into "Very High Research Activity", "High Research Activity", and "Research Universities". The Carnegie Foundation compiles their dataset by ranking every degreegranting college and university in the United States (Carnegie Foundation, n.d.). The data was collected in 2003 and 2004 (Carnegie 2005 Edition, n.d.). The other school-level dataset, the U.S. News and World Report (US News) data was collected from that organizations website in 2012 (US News \& World Report, 2012). The U.S. News and World reports' school-level rankings are perhaps the most prominent numerical indicators of school reputation and are often cited by university administrators (Ehrenberg, 2002).

The ranking systems (department-level and school-level) were integrated with our national survey of graduate students by matching school name and program-relevant information provided by the respondents in all four datasets. The matching employed a conservative approach of checking for multiple schools by the same name and only matching when no ambiguity existed, such as in cases where multiple schools with similar abbreviations exist (e.g., $\mathrm{U}$ of $\mathrm{C}$ is not enough information to determine the exact school) or where school-types in the Carnegie data did not match with the information provided by the respondents (e.g., Carnegie data listed the school as not $\mathrm{PhD}$ granting). Given that the NRC data provided departmental data at the level of individual programs, we also matched at the departmental level for the NRC data according to the question in our survey about the respondent's area (e.g., social, clinical, developmental). To take a conservative approach, we matched for each respondent only if the NRC listing was unambiguous. For example, the NRC data is not a complete list of each program within each department and the respondents sometimes provided incomplete school names (e.g., $\mathrm{U}$ of C), so we checked for multiple schools by the same name, multiple areas overlapping within a department (e.g., the respondent indicated a developmental area but the department had developmental focus in multiple programs), multiple psychology departments within the school, and multiple campuses within the university each with a psychology department. Our goal was to avoid noise in the data to produce more accurate findings.

\section{Results and Discussion}

The purpose of the paper is to investigate two sets of variables from our national survey: academic accomplishments and subjective experiences while in graduate school. The findings are organized around (1) examining the relationship between those two sets of student variables and the rankings (department-level, school-level), (2) identifying the determinants of those two sets of outcome variables using multiple regression, and (3) examining the outcome variables year-byyear in the program to explain changes over time at different points in the graduate career.

\section{Student Variables and the Department/School Rankings}

\section{Ranking and accomplishments}

Do higher ranked departments/schools have more accomplished students? The answer is yes, but only to a small degree. Table 1 (at end of paper) reports the associations between department rankings, school rankings, and the variables from our graduate student survey. The rankings are associated with more total publications from students, higher number of in-preparation and ongoing projects, more posters, and almost every benchmark of academic success, but the association falls only within Cohen's benchmarks for medium to small effects (Cohen, 1988). Surprisingly, 
the relationship is positive for teaching experience as the primary instructor of a course. As department rankings improve (so lower number since rankings are 1 to 225) the number of times as the primary instructor also goes lower $(r=.15)$.

Given the large sample sizes (i.e., 1,767 for NRC variables, 2,372 for Carnegie data, 2324 for US News data) it is not surprising so many relationships are significant in Table 1 . What is notable is the lack of significance for the Diversity dimension. The generally nonexistent relationship between the Diversity dimension and the research variables (publications, publication-related questions, research activity) may imply a very positive outcome that research productivity is not associated with inequality when it comes to Diversity. The fact that the Student Support dimension is significant implies that providing student support does in fact help with research accomplishments. Later analysis will identify the predictive power of each dimension and tease apart which particular aspects of department and faculty characteristics impact student scholarship and experiences.

\section{Rankings and subjective experiences}

Do higher ranked departments/schools have more satisfied students? Table 1 shows that of all the experience-related variables, the only consistent relationship is with happiness with graduate school and autonomy. Higher ranked departments are not associated with more life satisfaction, or having good relationships with people in the program, or feeling competent. In other words, the average student at a better ranked program has more publications (as the previous analysis revealed) and higher feelings of autonomy and happiness with graduate school, but not feelings of competence, relatedness, or overall life satisfaction.

\section{Gender effects}

As seen in Table 1, there is a weak but significant relationship between gender and certain dimensional rankings. For the overall ranking systems (R-Ranking, Carnegie, US News), however, there are weak and non-significant associations with gender. To more fully understand the role of gender we conducted a correlation analysis between gender and the other items in our survey and found a generally weak gender effect for every achievement-related question (except for third author+ publications and number of conferences). For example, females had significantly less total publications $(r=-.08, p<.001)$, posters $(r=-.03, p=.08)$, teaching assistantships $(r=-.05$, $p<.01)$, and number of times as the primary instructor of a course $(r=-.05, p<.01)$. The results become stronger when examining first-author benchmarks, such as fewer first author publications $(r=-.13, p<.001)$ and fewer ongoing projects at first author $(r=-.13, p<.001)$. Similarly, all the life satisfaction and psychological needs satisfaction items showed significant effects. Females reported feeling less happiness with graduate school $(r=-.06, \mathrm{p}<.001)$, overall life satisfaction $(r=-.04, p=.02)$, autonomy $(r=-.08, p<.001)$, and competence $(r=-.10, p<.001)$, while at the same time feeling more stress $(r=.16, p<.001)$ and more positive relationships with people in the program $(r=.06, p<.01)$. At the same time, males and females felt similarly about recommending graduate school $(r=.02, p=.32)$ and their perceptions of obtaining their preferred employment $(r=-.02, p=.42)$.

\section{Identifying the Determinants of the Student Variables}

\section{Number of publications}

Given the emphasis within the research community on number of publications, what predicts having more of them? Although each ranking system separately was associated with total number of publications in the prior analysis, after controlling for each other it is only the department rankings that matters $(\beta=-.15, p<.001$ for NRC R-ranking), with school rankings having no effect ( $\beta$ 
$=.01, p=.83$ for US News; $\beta=-.02, p=.61$ for Carnegie) with overall Adjusted $\mathrm{R}^{2}$ of .02 ( $F(3$, $1745)=13.58, p<.001)$. An undergraduate student currently in the midst of deciding which graduate program to attend who desires publications while in the program may want to consider that a department with a good reputation within an otherwise not-well ranked school may be more beneficial than attending a school solely with a reputable name.

To more fully understand the predictors of publications, multivariate regression analysis is reported in Table 2 (at end of paper) using three blocks of predictors: student achievements, rankings, and student experience variables (satisfaction/needs). For the student achievement variables we included the most relevant student accomplishments possible (e.g., first-author publications could not be included since it formed partial basis for total-publications). For the ranking variables we included all three rankings systems but used the dimensional ranks of the NRC data instead of the overall R-Rankings since the dimensional rankings (Research Activity, Student Support, Diversity) form the basis for compositing the overall R-ranking and thus tap the same underlying constructs, while at the same time the three dimensions also provide more detailed information about the potential predictive power of each of three separate aspects of department attributes. We conducted the analysis through hierarchical regression to identify if each block provided any additional value while also competing each against each other to identify each unique predictive effect. Given the large number of variables in Table 2, only the significant effects are provided to help the reader parse the breadth of the data. As see in Table 2, only particular aspects of the department and faculty-level characteristics impact total number of publications, including a surprising association of less happiness for more total publications.

Although at first blush these results may seem counterintuitive, comparing to the regression analysis for "number of times as primary instructor" reveals a picture of the graduate student lifestyle. First, the significant NRC dimensions are positively associated with teaching experience but negatively associated with publications, indicating that total publications is associated with better ranked programs but more teaching experience is associated with worse ranked programs. Second, in terms of the Research Productivity dimension, a follow-up regression analysis using the four individual attributes of that dimension found that a lower "percent of faculty grants" was associated with a lower number of student publications but higher number of times as a primary instructor. The Research Productivity dimension composed four individual items. Total publications was related to average number of publications per allocated faculty member $(\beta=.10, p<$ $.001)$ and percent of faculty with grants $(\beta=.09, p<.001)$, but not related to average citations per publication or awards per allocated faculty member, with overall Adjusted $\mathrm{R}^{2}$ of $.03(F(4,1792)=$ $13.76, p<.001)$. Being the primary instructor was related to all attributes $(\beta=.07, p=.02$ for publications; $\beta=-.12, p<.001$ for citations; $\beta=-.11, p<.001$ for grants) except for awards $(\beta=$ $.01, p=.82$ for awards), with overall Adjusted $\mathrm{R}^{2}$ of $.03(F(4,1766)=13.21, p<.001)$. Lack of support may force some students to seek outside financial employment. If so, how do the time restraints of teaching courses impact productivity. The answer is not at all.

As seen in Table 2 there is a modest association between being a primary instructor and publication-related accomplishments, such as in-submission, in-preparation, and posters; although that may be explained by the underlying mechanism of a hardworking and committed student. Third, both research productive (total publications) and teaching productive (number of times as primary instructor) students report having less happiness with the program. Why are they less happy with the program if they have more publications and other benchmarks of academic success? Interestingly, only the teaching productive are associated with more overall life satisfaction. They also experience less positive relationships with people in the program. The students who are teaching may experience greater overall life satisfaction but the cost may be fewer connections to people in the department. 


\section{Predicting rankings}

The ranking systems were compiled from the departmental and faculty characteristics. Can student achievements or student satisfaction variables predict a high ranked program? As see in the first few columns of Table 2, neither the block of student achievement variables nor the block of satisfaction variables explained much variance of the ranking systems (Adjusted $\mathrm{R}^{2}$ of .06, and $.00)$. Although one would have hoped that a highly ranked department is dependent upon student achievements and experiences, there was not much predictive power of the student variables. That said, some variables did emerge as predictors, notably publications and autonomy for the department-level (NRC) ranking system. Strangely, there were a few positive predictors, such as number of times as primary instructor and competency, indicating that better ranked departments fared worse on those variables. However, to be fair, the items composing the NRC rankings are not necessarily intended to capture the student-level experience. It would be helpful for the field (and for students) if there was a ranking system based upon the variables they desire in a program such as research productivity, teaching productivity, and positive student experiences.

\section{Predicting student experiences and satisfaction variables}

Previously we analyzed what predicts student achievements, such as total number of publications, but what is associated with whether they actually like graduate school or feel competent? The answers may have utility not only for prospective and current students but also for administrators and faculty interested in retention and program improvement. As a concise summary of the data for the six satisfaction variables, the results from Table 2 reveal that achievements and rankings are contributing little to the quality of the students' experiences.

As an example, publications are predicting more competence but not overall life satisfaction, stress, relationships, or autonomy. Even more striking is how few significant relationships emerge for the ranking systems. A better ranked department or school has little to no bearing on the students' experiences at that department/school. This is surprising given that the variables used to compose the NRC dimensional ranks, for example, are variables that would be expected to impact student happiness and stress, such as percent of faculty with grants, number of publications per faculty, and percent of first year students with full financial support (see Assessment of Research Doctoral Programs (n.d.), which provides detailed information on the NRC website about how each individual item composing the dimensional rankings was collected and processed).

What is associated with happiness and stress during graduate school? In terms of stress, the answer is not publications, posters, teaching experience, or any of the other achievement questions. Instead, stress is associated with less competency and autonomy. In other words, it is not the objective benchmarks of success that are associated with stress, but the perception of academic expertise. Similarly, the strongest predictors of happiness with graduate school are the other satisfaction variables, not rankings or academic accomplishments.

The same finding emerges for recommending a graduate school. The strongest predictor of recommending a graduate school was happiness and the satisfaction variables related to the three psychological needs (relationships, autonomy, competency). The implication is that from the student's perspective, recommending their program to another is based upon the day-to-day aspects of good relationships, autonomy, and feelings of competence, not the reputation of the program or their own achievements such as publications and posters.

The strongest predictor of employment chances was also a set of satisfaction variables. To provide context for this finding, Table 1 revealed an interesting result that department rankings were positively associated with employment chances, indicating that worse ranked programs are associated with perceiving a greater chance of preferred employment. Table 2 now shows that feeling happy and competent is associated more strongly with employment chances than having actual 
publications. That may be denial, especially given the way hiring committees evaluate applicants based upon publications rather than their perceptions of themselves.

\section{Mediational models and publications}

Although the number of publications is not directly influencing many of the variables in Table 2, it does predict competency, and competency is strongly associated with the other variables, thus suggesting a mediational model. Using the Sobel test macro by Preacher and Hayes (2004), we tested that mediational model of publications influencing the other variables through competency. For example, although total publications was not significant in Table 2 for recommending graduate school, it does influence recommending graduate school through feelings of competency (Publications $\rightarrow$ Competency $\rightarrow$ Recommend Graduate School) with a significant Sobel test of mediation $(z=9.28, p<.001)$. The same model also occurred for expected chances of employment (Publications $\rightarrow$ Competency $\rightarrow$ Employment Chances), $z=9.06, p<.001$. Using the other satisfaction variables as the mediators (autonomy, life satisfaction, happiness, stress) produces similarly significant results ( $p$ s $<.001$; but n.s. for "good relationships"). In other words, it appears the satisfaction variables could be the process by which total number of publications influences perceptions of employment and recommending graduate school.

\section{Examining the Student Variables Year-by-Year}

\section{Average student accomplishments}

What are the average student accomplishments across the graduate school experience? Table 3 (at end of paper) provides data about how the typical graduate student performs at each year in the program. Part of the purpose for conducting the current research was the authors' curiosity in how they compared to their similarly situated peers. Given the wealth of data it's not possible to statistically present every possible combination of analyses, and different readers may be particularly interested in different variables and yearly comparisons, so the inclusion of the specific information in the tables allows the reader to calculate their preferred pairwise comparison. D. B. Wilson,(2011) provides a free online spreadsheet for calculating comparisons (significance and effect size) between any two data points by using the summary statistics provided in the tables. A few important results are worth highlighting.

For example, number of publications rises to a peak at year 6 and then tappers off in year 7 and 8 . Line graphs are provided instead of bar graphs since they allow the reader to see progression over time, which is the intended purpose behind analyzing data according to year in the program. As seen in Figure 1, there is an inverted U-shape that peaks at year 6 for total publications and first author publications. Why? It is possible that students with greater productivity procure employment in year 6, resulting in students left in the program with less productivity. Or, maybe students with low productivity remain in the program for more years to attain their expected level of accomplishments. Do the remaining students ever reach that preferred level of increased productivity? As a whole, they do not. Figure 1 shows a steady decline. However, given that variation within each year increases year-by-year, there is reason to believe that some advanced graduate students do increase productivity. Finally, given the leading emphasis on publications within the field, the mean, median, and mode levels were calculated for the total number of publications in Table 3, since the mean is the average level of publications, the median is resistant to an outlier number of publications, and the mode represents the true majority of people for sake of comparison. Notice that zero publications is the mode for many of the years. 


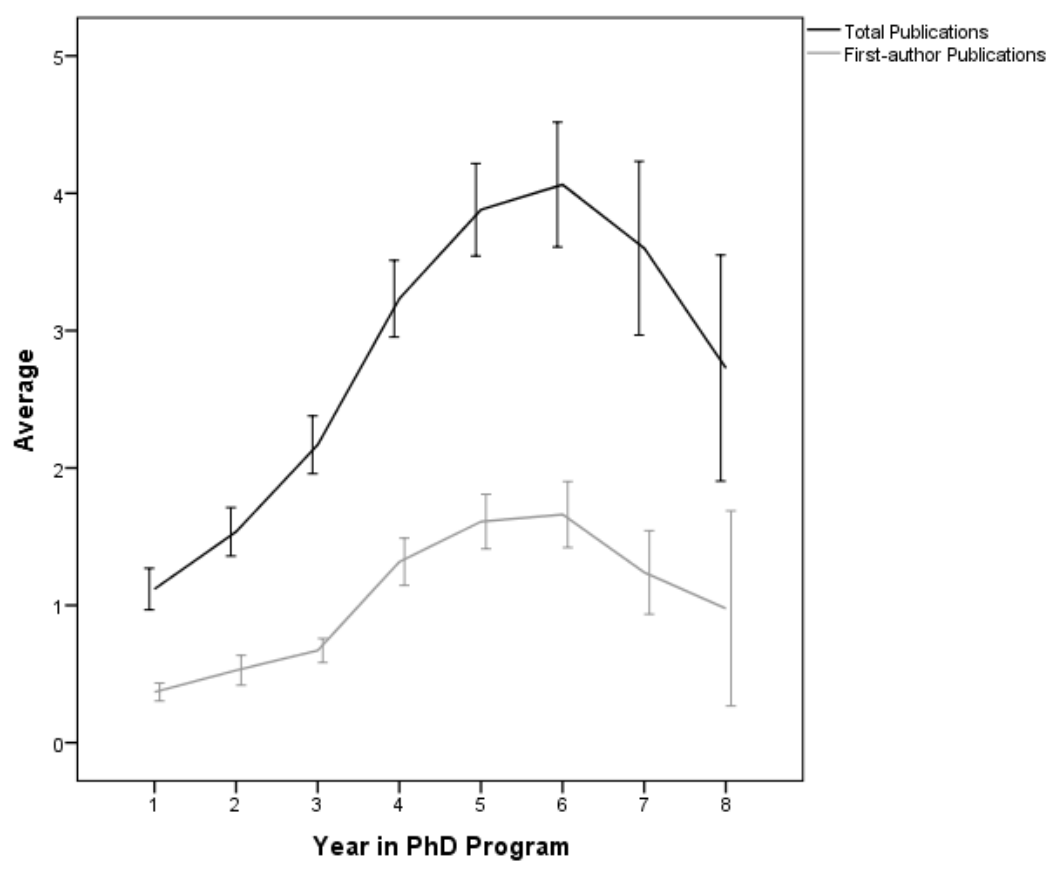

Figure 1: Line graphs with 95\% confidence intervals for "Total Publications" and "First Author Publications"

\section{Stress in graduate school}

Does stress in graduate school increase or decrease over time? The answer is neither. The stress is constant. As you can see from Figure 2, which shows year-by-year progression, $\mathrm{PhD}$ students are stressed at the same level throughout their graduate career. There is more variation in the stress level as the number of the years in the program increases, and yet the average stress level of first year students is equivalent to the stress level of advanced graduate students. Does this imply that graduate school is uniformly stressful from day one, or that graduate students learn to adjust but the burdens placed upon them by graduate school is ever increasing? The second notable finding from Figure 2 is that overall life satisfaction is also relatively uniform as students progress through their program. Is being in graduate school, irrespective of the year in the program, contributing toward a general sense of accomplishment and satisfaction? If so, that accomplishment and satisfaction is not paralleling a sense of happiness with the program. The third finding from Figure 2 is that although all three variables start at the identical place at the beginning of the program, happiness decreases year-by-year for every year in the program. $\mathrm{PhD}$ students start their graduate careers in the top part of the 7-point scale, and then they gradually become unhappier with graduate school, ending their graduate career in the bottom part of the 7-point scale. The biggest plunge in happiness occurs after year 6 which may suggest the same underlying cause for the inverted U-shape found for publications. Are PhD programs destroying people's happiness? 


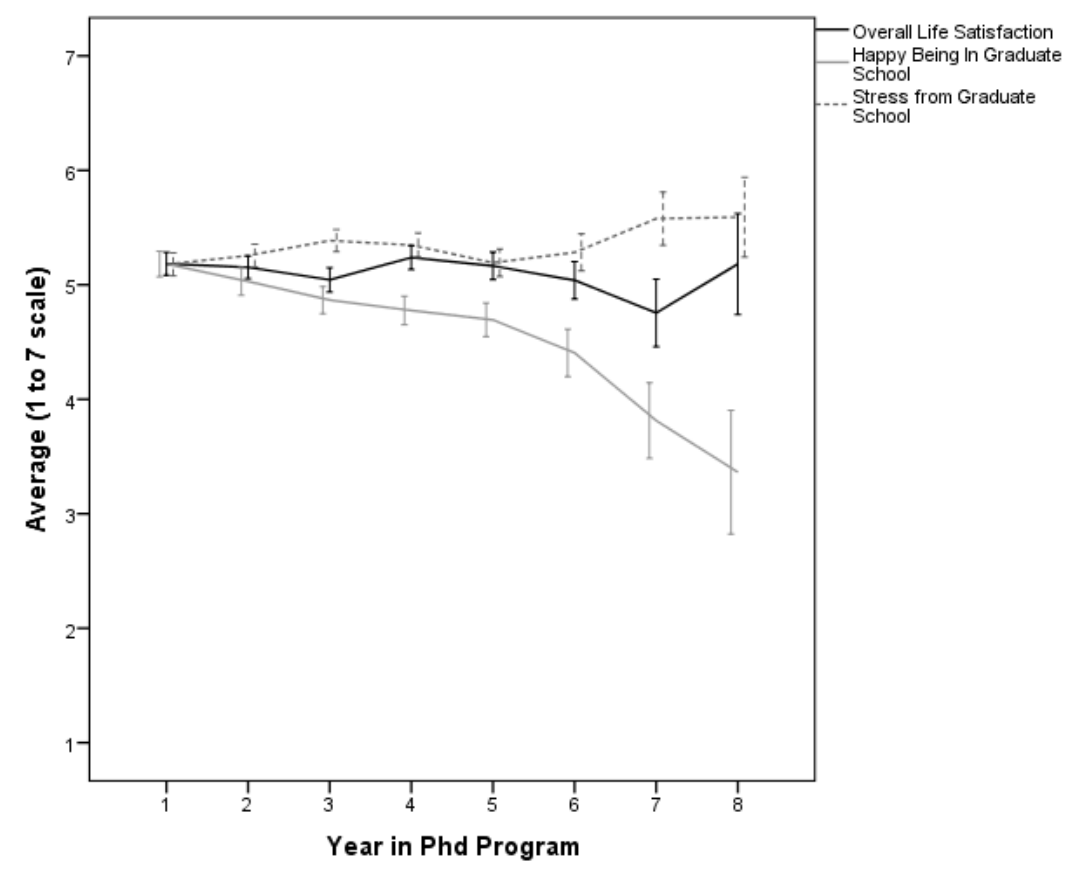

Figure 2: Line graphs with 95\% confidence intervals for "Overall Life Satisfaction", "Happiness Being in Graduate School", and "Stress from Graduate School"

\section{Student needs}

How does graduate school meet student needs? Figure 3 tells an interesting story about how PhD

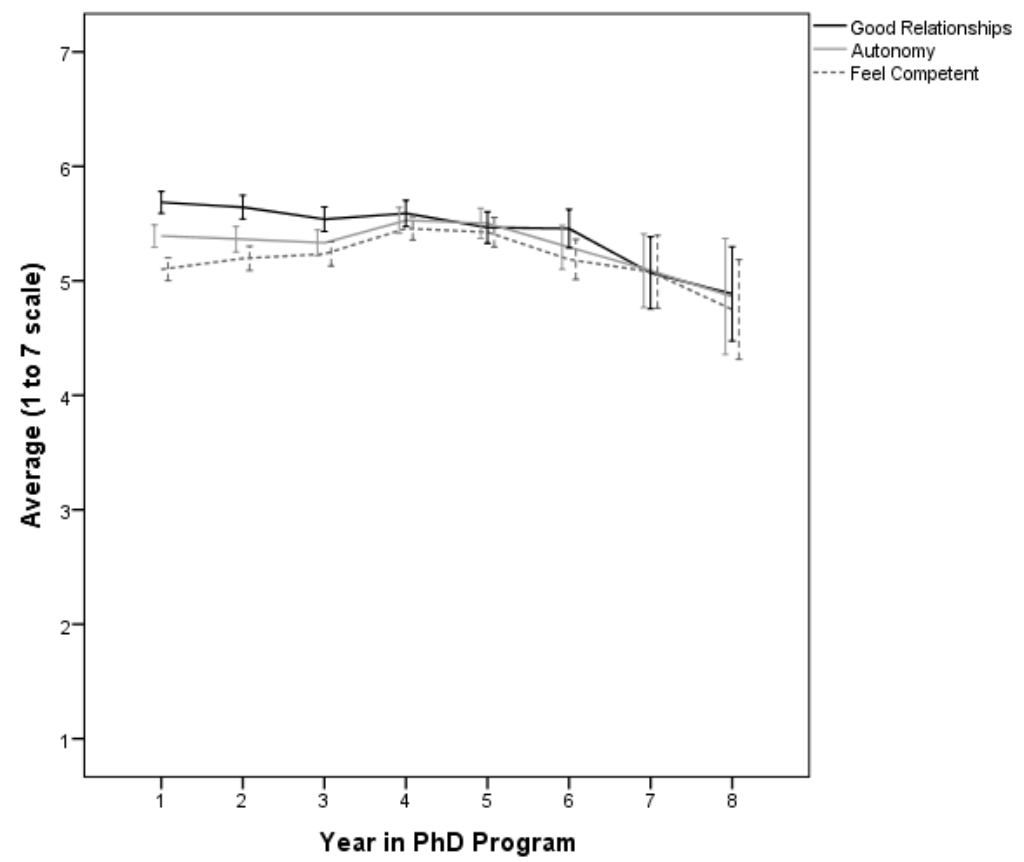

Figure 3: Line graphs with 95\% confidence intervals for " Good Relationships", "Autonomy", and "Feel Competent" 
students experience their graduate careers. The first notable finding is that all three basic needs within self-determination theory begin at different levels as the start of the graduate career in which having good relationships with people in the program exceeds the level of autonomy, which then exceeds the feelings of competency. Second, although the three variables start at different levels at the beginning of the career, they all synch together in the middle of the career around year 4 and remain joined until graduation from the program. It appears having good relationships with people in the program steadily decreases year-by-year. At the same time, competency and autonomy follow somewhat similarly to the inverted U-shape found for researchrelated benchmarks. A clear positive aspect of the data, however, is that all three remain on average in the top half of the 7-point scale for the entire graduate school experience. That said, it is somewhat disheartening to learn that people report having less and less positive relationships with people in the program every year that passes.

\section{Recommending the program}

Do PhD students recommend their program? The answer is less and less over time. As seen in Figure 4, there is a constant decline every year. Notice the trend for "recommending the program" does not match the trends reported earlier for the questions about accomplishments such as publications, projects, and posters.

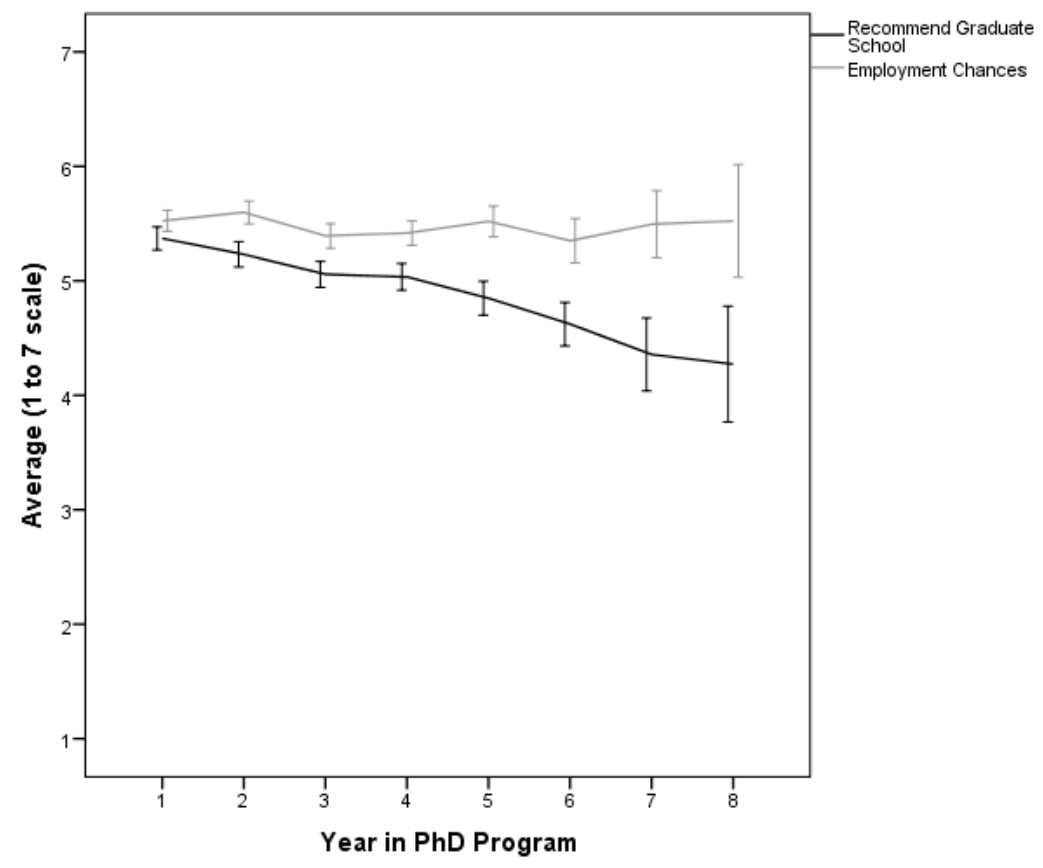

Figure 4: Line graphs with 95\% confidence intervals for "Recommend Graduate School" and "Employment Chances"

\section{Chances of employment}

What do students feel are their chances of employment? A final finding worth noting from the dataset is the relatively uniform perception at every year in the program that the type of job $\mathrm{PhD}$ students want will become a reality. As seen from Figure 4, first year students are no more, or no less likely, than students in later years of the program to believe their ideal job will be obtained. Although the variation is larger as graduation nears in later years of the program, the average $\mathrm{PhD}$ 
student has a constant perception of obtaining the ideal employment. Since that question specifically asks respondents about employment in the "type of job you want" after graduating, irrespective of the type of job, all graduate students are feeling strongly about obtaining the preferred employment even though their individual accomplishments vary. In other words, even though the student achievements and experiences vary greatly year-by-year (e.g., for publications, posters, teaching assistantships, number of times as primary instructors, happiness with the program, relationships with the people in the program, feelings of autonomy, and feelings of competence), the belief in obtaining employment persists. Plus, not only is the belief constant, but it is constantly high. On a 7-point scale, the trends presented in Figure 4 show that the belief is near the top of the scale.

\section{Conclusions}

The findings highlighted in this paper are some of the possible relationships that a reader might be interested in, given the breadth of the data, focusing on two central variables: academic achievement and the subjective student experience. We invite the reader to examine variables that are explored in Table 1-3 but were not highlighted here such as other publication-related questions, research activity, conferences, time to graduation, and post-graduate plans. We chose to highlight the two variables of most interest to prospective and current students during their graduate career, while at the same time focusing the analysis on explaining the associations and determinants of those two sets of variables. It is hoped that this unique integration of datasets can provide empirical insight into forces that may be at work in the lives of students throughout psychology to help current and prospective students, administrators, and faculty supervisors better understand the graduate school experience in order to create needed improvements for student retention and success at the graduate level.

For example, the life of a PhD psychology graduate student is marked by a unique combination of three broad trends in the data: (1) a strong inverted U-shaped relationship for publications, with a similar but weaker relationship for feelings of competency autonomy, (2) relatively flat but high levels of stress, life satisfaction, and employment chances, and (3) generally diminishing levels of happiness with graduate school, recommending graduate school, and having good relationships with people in the program. It appears that students do better to a peak (e.g., publications, competency, autonomy) but feel worse (e.g., lower happiness, less recommending the program, lower perceptions of good relationships with people in the program). And yet, overall life satisfaction is constant (and high). At the same time, the regression analysis revealed the individual determinants of both the objective achievement variables and the subjective experience variables, with interestingly only a weak and generally nonexistent relationship between the two. The relationship between department rankings and the student variables, on the other hand, depended upon the type of ranking, with the most consistent relationships for the Research Activity and Diversity dimensions, but less so for the Student Support dimensions. However, the nature of those relationships varied in valence depending upon the type of student-level outcome variable, with both positive and negative relationships to department/school rankings.

\section{Limitations and Implications for Future Research}

As shown by the complex interrelationships amongst the department-level and student-level variables it may be important for the field to re-evaluate the $\mathrm{PhD}$ educational experience in a way that fosters the type of achievements and student experiences that are central to graduate students.

Ideally, mechanisms should be developed at the program level that takes into account each unique predictor of these outcome variables (Research Activity, Diversity, Student Support, publications, teaching experience, autonomy, competency, etc.) to promote training improvements organized around year-by-year progress and growth. Moreover, given that the student-level variables had no 
predictive power for the ranking systems, developing a new ranking system of departments based upon the variables important to students would be a useful benefit to the $\mathrm{PhD}$ application process. A valuable endeavor may also entail an annual or decadal survey of these variables to identify the multifaceted nature of the graduate school experience across the history of the field.

The current research was conducted on psychology graduate students. The forces that work on the "average" student within or across disciplines may differ from the forces that may characterize any one individual graduate student's experience. Still, from our anecdotal experience with graduate students in other fields, similar forces work across disciplines. Indeed, the experience of "doing better, but feeling worse" is not limited to psychology or even to graduate school, but may be a symptom of any environment where ever higher levels of achievement are demanded (e.g. see Barry Schwartz's The Paradox of Choice). Similarly, the faculty and staff who are responsible for the development of graduate students across disciplines likely have similar questions about the effect of school reputation, department reputation, and department policies, with respect to student achievement and experience. The current research can by no means definitively answer these questions across all disciplines, but, as some of the first quantitative work in this area, it can inform current conversations about the direction of higher education and the value of the graduate school experience.

\section{References}

American Psychological Association. (2007). Graduate study in psychology. Washington, DC: Author.

Assessment of Research Doctoral Programs. (n.d.) Retrieved from http://sites.nationalacademies.org/PGA/Resdoc/index.htm

Carnegie Foundation. (n.d.) Retrieved from http://classifications.carnegiefoundation.org

Carnegie 2005 Edition (n.d.). Retrieved from http://classifications.carnegiefoundation.org/resources

Cohen, J. (1988). Statistical power analysis for the behavioral science ( $2^{\text {nd }}$ ed.). Hillsdale, NJ: Erlbaum.

Deci, E. L., \& Ryan R. M. (2000). The 'what' and 'why' of goal pursuits: Human needs and the selfdetermination of behavior. Psychological Inquiry, 11, 227-268.

Ehrenberg, R. (2002). Reaching for the brass ring: The U.S. News \& World Report rankings and competition. The Review of Higher Education 26 (Winter 2002), 145-162.

History of National Academies. (n.d.). Retrieved from http://www.nationalacademies.org/about/whoweare.html

National Academies Press. (n.d.). Retrieved from http://www.nap.edu/rdp

National Research Council. (2011). Retrieved from http://sites.nationalacademies.org/PGA/Resdoc/PGA_044475

Ostriker, J. P., Holland, P. W., Kuh, C. V., \& Voytuk, J. A. (Eds.). (2011). A data-based assessment of research-doctorate programs in the United States. Washington, DC: The National Academies Press.

Preacher, K. J., \& Hayes, A. F. (2004). SPSS and SAS procedures for estimating indirect effects in simple mediation models. Behavior Research Methods, Instruments, \& Computers, 36, 717-731.

Schwartz, B. (2005). The paradox of choice: Why more is less. New York, NY: Harper Perennial.

Stenstrom, D. M., Curtis, M., \& Iyer, R. (2013). School rankings, department rankings, and individual accomplishments: What factors predict obtaining employment after the PhD? Perspectives on Psychological Science, 8, 208-217.

US News \& World Report. (2012). National university rankings. Retrieved March 10, 2012 from http://colleges.usnews.rankingsandreviews.com/best-colleges/rankings/national-universities/data 
Wilson, D. B. (2011). A spreadsheet for calculating standardized mean difference type effect sizes. Retrieved from http://mason.gmu.edu/ dwilsonb/ma.html

\section{Biographies}

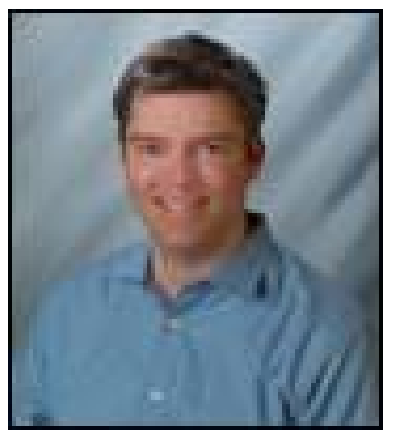

Doug Stenstrom is an Associate Professor at California State University Los Angeles. He holds a J.D. from Loyola Law School, and a Ph.D. in Psychology from the University of Southern California.

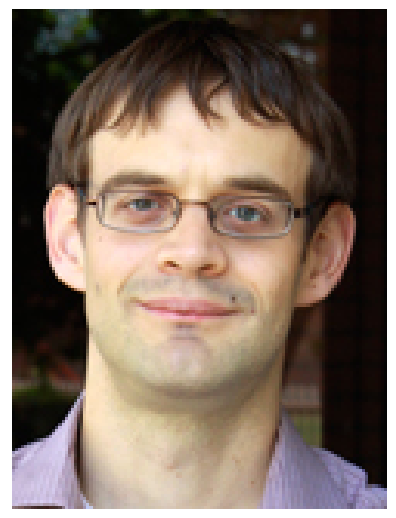

Dr. Mathew Curtis is a Clinical Associate Professor in the Annenberg School for Communication and Journalism at the University of Southern California. His research interests include emotion, social comparison, and linguistics. He teaches a range of graduate classes with an emphasis on research methods, statistics and marketing.

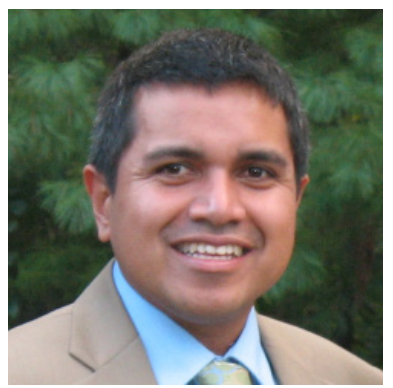

Ravi Iyer occupies a unique space at the intersection of data science and psychology. He is the chief data scientist for Ranker, a consumer internet platform that collects millions of monthly consumer opinions, and the executive director of Civil Politics, a non-profit that uses technology to bridge the divide between practitioners and researchers in moral psychology. He holds a Ph.D. in social psychology from USC and can be reached at @RaviDataIyer or ravi@ranker.com. 


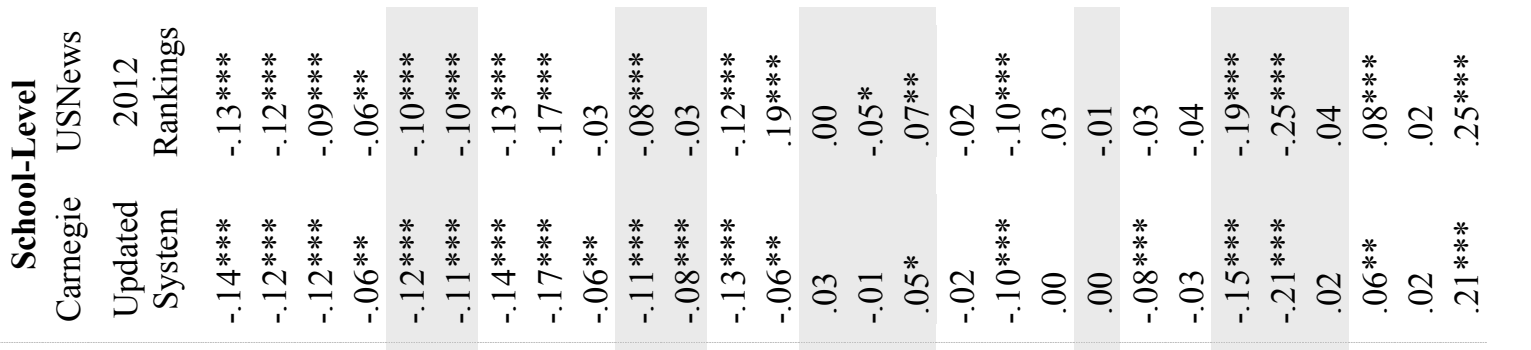

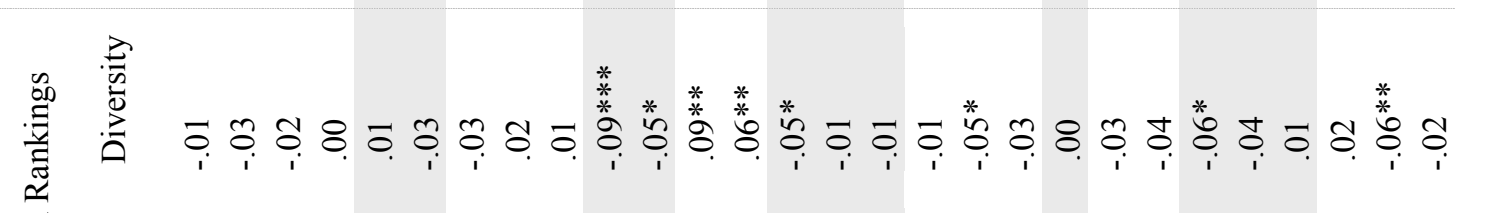

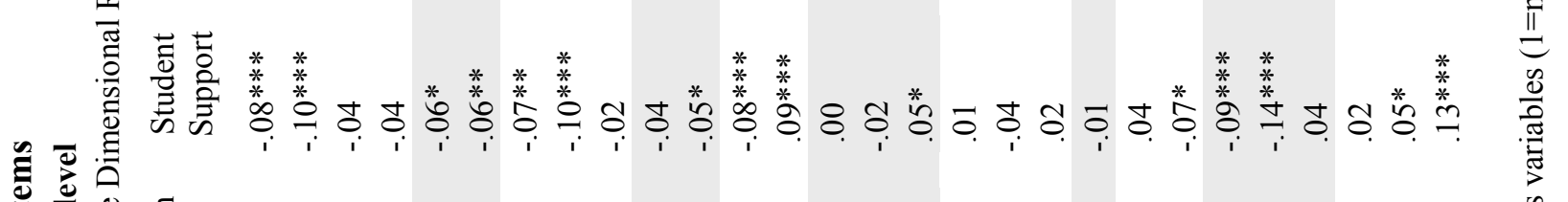

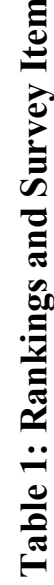

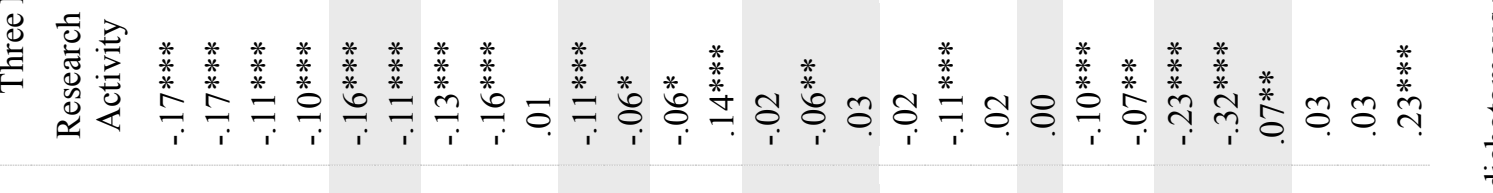

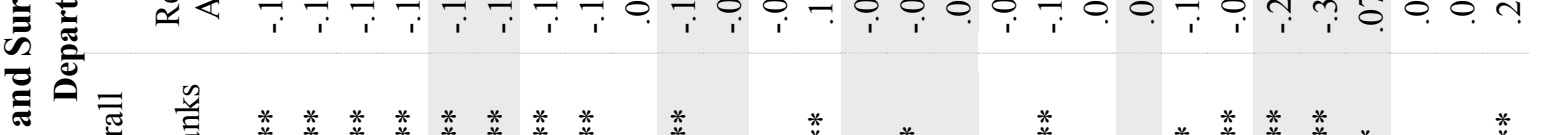

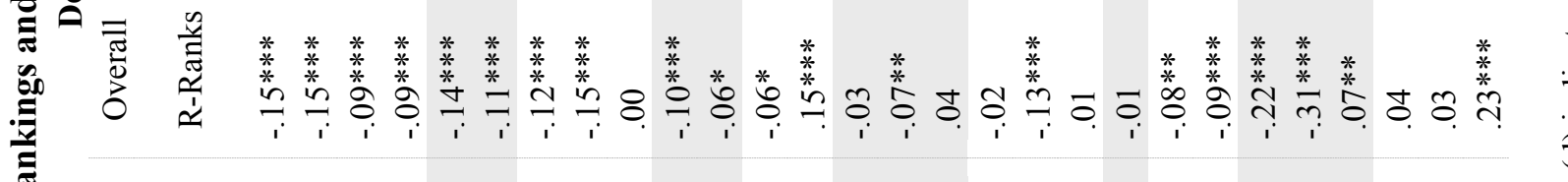

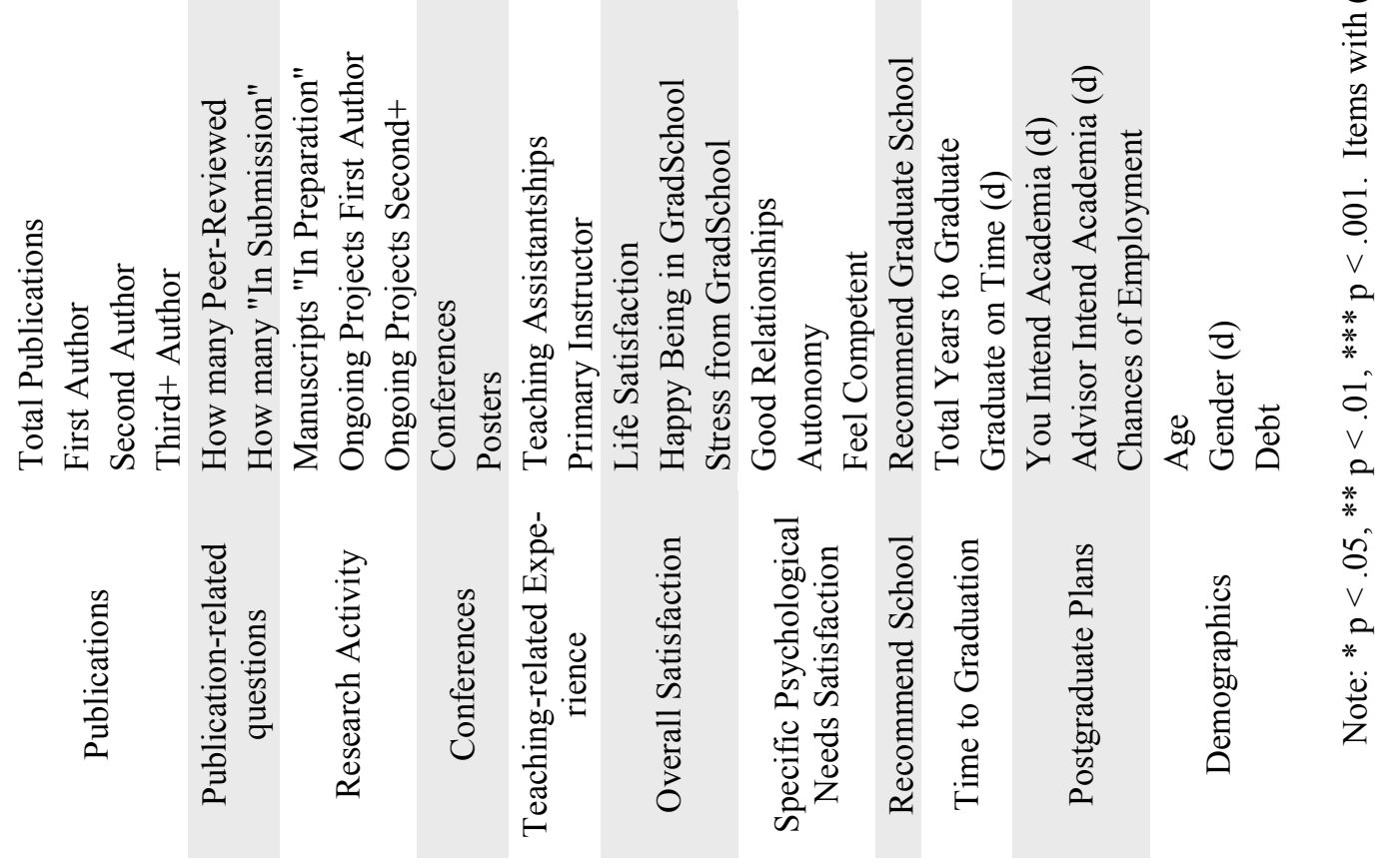




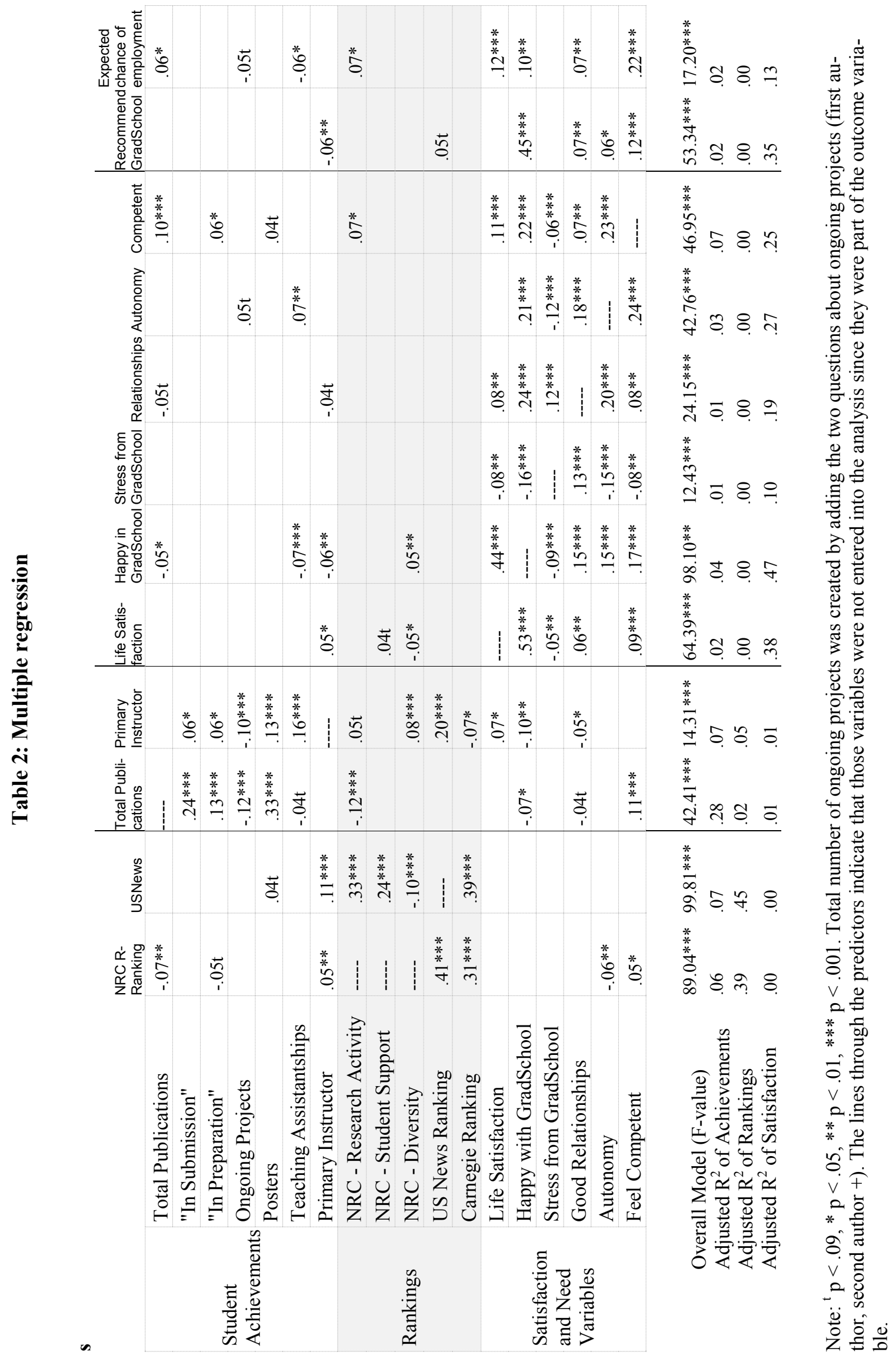




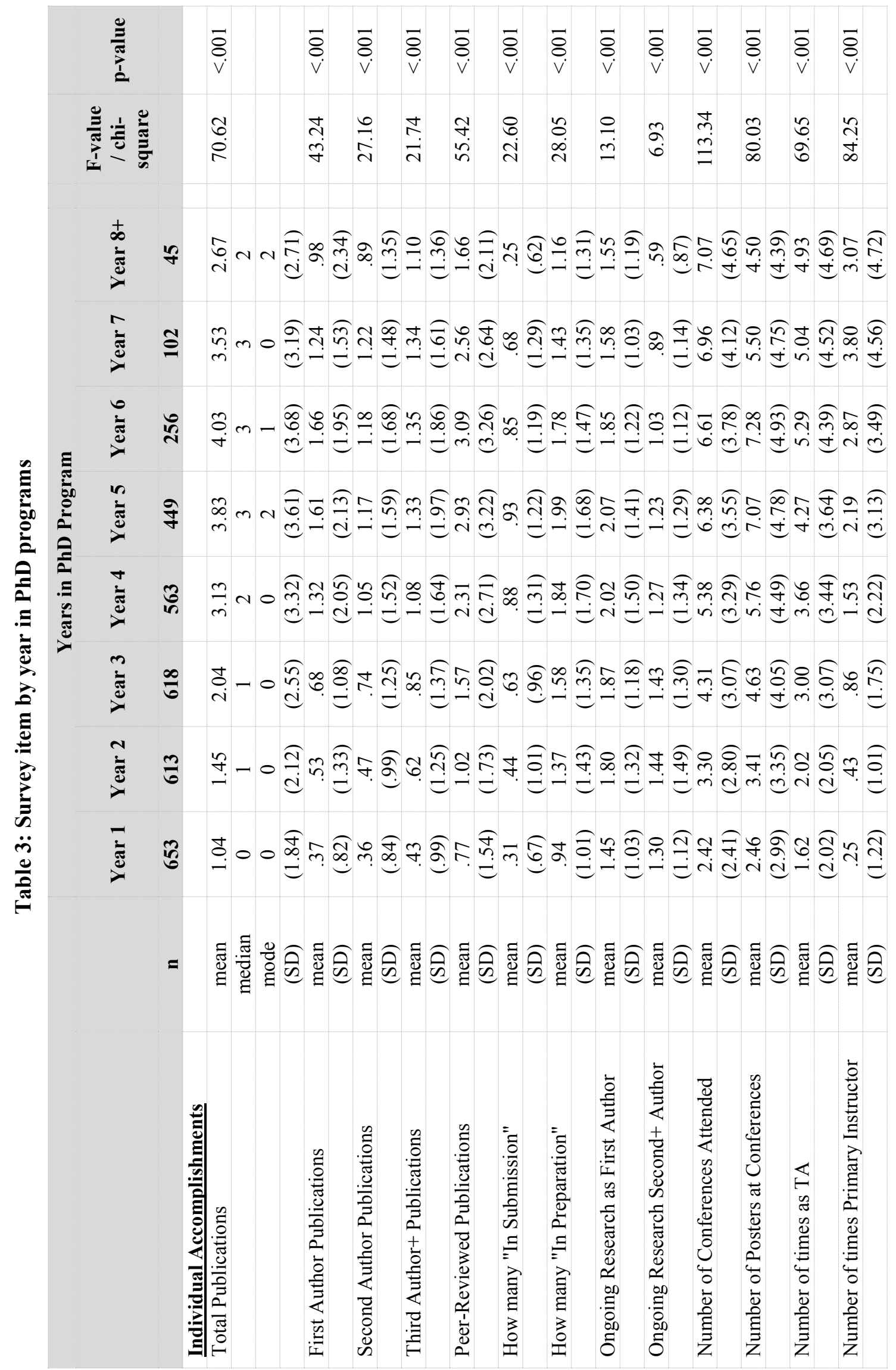




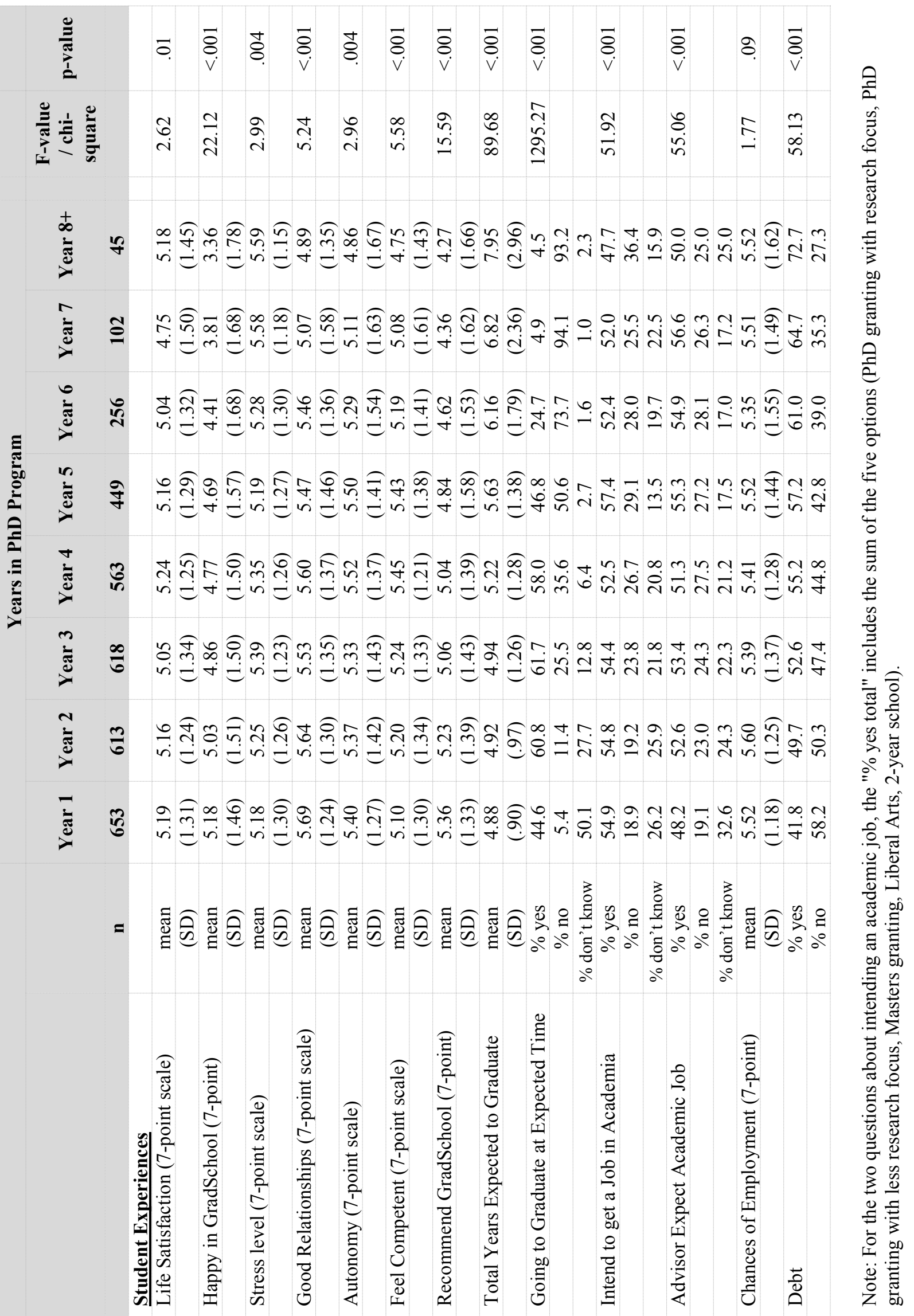

